\title{
Can Urban Water Markets Work? Some Concerns
}

\section{Lin Crase, Suzanne O'Keefe and Brian Dollery ${ }^{1}$}

There is now considerable interest in exploring the usefulness of markets as a means of dealing with urban water provision in Australia. Buoyed by the successes of markets in electricity and telecommunication services, the reformist's gaze has now turned to urban water, where ongoing water shortages have forced water utilities to invoke widespread restrictions to bring demand into balance with limited supply. Amongst the arguments proffered in favour of urban water markets is the view that such arrangements would result in improved allocative efficiency (see, for instance, Productivity Commission 2008). It is also contended that markets should give rise to clear incentives for timely investment in alternative water sources and new technologies which might ultimately alleviate the necessity for water restrictions.

The National Water Initiative (NWI) of 2004 established important actions and objectives to advance water reform. Notwithstanding the subsequent release of the Howard Government's National Plan for Water Security followed by the Rudd Government's Water for the Future manifesto, the work program outlined in the NWI continues to guide policy development, particularly in the area of urban water reform. Paragraph 92 (iv) of the NWI called for a 'review (of) the institutional and regulatory models for achieving integrated urban water cycle planning and management, followed by best practice guidelines' (NWC 2005) and this was later broken into several priority tasks. One of these relates to the requirement to 'facilitate water trading between and within the urban and rural sectors' (NWC 2005). In order to give effect to this and related objectives, a Joint Steering Committee for Water Sensitive Cities was established. The Committee subsequently commissioned several pieces of work to explore the means of introducing water markets in the urban setting.

In a related, but much earlier, development, the introduction of water markets for agricultural water users commenced in earnest in the early 1990s and has clearly yielded substantial economic gains (see, for instance, RIRDC 2007). The capacity of some agricultural industries and/or firms to cushion against the impacts of the recent drought has been substantially enhanced by access to the water market. However, the present operation of rural water markets is likely to vary in significant ways from a potentially atomistic urban water market

\footnotetext{
${ }^{1}$ School of Business, La Trobe University, l.crase@latrobe.edu.au; School of Business, La Trobe University, s.okeefe@latrobe.edu.au; School of Economics, University of New England, bdollery@une.edu.au.
} 
where individual households 'trade' water. In this context, a question arises about the extent to which the perceived successes of the rural water market might be drawn upon as evidence of the merits of similar reforms for urban users, especially households.

In seeking to answer this question it might be helpful to consider those factors that have been important in delivering the economic gains that have flowed from rural water markets. In this regard, it may also be prudent to reflect on some of the well-documented shortcomings of rural water markets (see, for instance, Brennan 2007) to at least temper the policymakers' ostensible enthusiasm for urban water markets. It is thus the purpose of this paper to reflect upon these issues in the hope of informing the policy debate on the potential for water-market reform in urban areas. In essence, the paper presents the case for a cautious approach to urban water markets, particularly where the scope for inter-sectoral trade at the aggregate level has not yet been fully developed.

The paper itself comprises five additional parts. Firstly, we describe the features that have underpinned the success of rural water markets, focusing specifically on what is euphemistically referred to as 'temporary' trade. Second, the limitations revealed during the development of rural water markets are addressed before turning to a comparison of the characteristics of rural and potential urban water-market participants. The penultimate section is used to consider a range of related matters, such as pricing, ownership and institutional design issues. The paper ends by offering some brief concluding remarks.

\section{Successes of rural water markets}

At the outset it needs to be acknowledged that rural water markets are dominated by 'temporary' transactions. In other words, the vast majority of resource re-allocation in irrigation occurs on a seasonal basis and permanent trades, which might be associated with enduring structural adjustment, remain modest by comparison. ${ }^{2}$ Nevertheless, the thriving temporary water market in the southern Murray-Darling Basin is testament to the perceived usefulness of the market for participants (see, for instance, RIRDC 2007).

The motivation for temporary transactions comes from several sources, not least the heterogeneity of farming enterprises and farmers themselves. Put differently, if every farmer was growing the same crop and had relatively similar demands, the scope for trade between parties would be severely limited. It is these marked differences and the potential to bring together enterprises with different calls upon the resource that is critical in this context. After all, this is the premise upon which markets are founded - individuals or groups need to hold valuations and preferences that are so different that exchange can take

\footnotetext{
2 This is particularly the case for permanent interstate trade that has been substantially stymied by the arduous administrative arrangements that attend 'tagging'.
} 
place and the collective gains are more than the costs of bringing about the transaction.

Firstly, the historic allocation of the resource by the state now bears only a weak correlation to the different water demands of enterprises within irrigated agriculture. For example, dairy farming, which can use as much as 10-15ML per hectare, must now compete for water against horticulture cropping which can use half that or less. In addition, the value of the output from these enterprises can also be expected to vary markedly over time, thereby driving demand for re-allocation, albeit often on a temporary basis. Moreover, there are important disparities within enterprises where management expertise heavily influences water use (and profitability). A related feature of this heterogeneity is the differing capacities of market participants to employ substitutes (for example, dairy farmers can substitute grain or silage for water whilst other industries, such as permanent horticulture, cannot). Similarly, some annual enterprises have the option of shutting down completely when water is in short supply, thus affording the opportunity to on-sell any residual water allocations. There are also differences in risk preferences, which can stimulate trade amongst farmers.

Secondly, water is often a vital and substantial input to the production system in irrigated agriculture, at least in volumetric terms. Thus, access at a critical point in the season can represent the difference between a very profitable crop and one that generates substantial losses.

Thirdly, most participants in this market are relatively well-versed with hydrological realities (for example, they know that it will cost money to transfer water uphill and they know the cost of lifting water from an aquifer). These buyers and sellers are also generally familiar with the legislative impediments (or ease) associated with accessing different water sources, such as groundwater - possibly even more so than some regulators.

In a related vein, most of those involved in this market have at least a rudimentary knowledge of the relationship between inputs and outputs. Even the most rustic yeoman would be able to give approximations of the consequences of an extra megalitre of water, here or there, or could roughly calculate the fodder required to substitute for water.

Also, the rural participants in this market face relatively low transaction costs. $^{3}$ The temporary water market has always been keenly promoted by the irrigation sector. In fact, irrigation corporations such as Murray Irrigation Limited and Goulburn-Murray Water have been the champions of the temporary water market and were amongst the first to offer online technologies to facilitate water

\footnotetext{
${ }^{3}$ Unlike the constraints that currently confront someone in a communal irrigation scheme wishing to sell water permanently.
} 
trade. This has not only reduced the transaction costs of farmers who chose to buy and sell water, it has also reduced the costs that would otherwise have to be borne by government to aid in the establishment of the market.

It should be remembered, too, that agricultural participation in this market is sanctioned by government in both a legal and moral sense. There is no innuendo suggesting that trading water between farmers is 'un-Australian'. This observation carries through to the treatment of rural water trade by the press. An agricultural purchaser of water is seldom portrayed as someone draining the life-blood from a desperate seller. This makes the political cost of market participation relatively low for this group.

In important instances the administering organisation charged with physically delivering water between buyer and seller shares much in common with the trading partners. For example, in Victoria, Goulburn-Murray Water, which has responsibility for managing bulk flows to all water users in its area of operation, also has a substantial role in managing irrigation infrastructure for the benefit of farmers.

Finally, participants in the rural temporary water market are generally aware that the long-term entitlements they hold over water are likely to increase in value, in part because of the increasing uncertainty that circumscribes the status of water rights and the volumes of water involved. It can thus be argued that this is one of the major drivers of temporary water trade in the rural water market. In this context it is somewhat ironic that one of the acknowledged weaknesses of the market for permanent water-access rights has simultaneously bolstered participation in the market for temporary trades.

\section{Failings of the rural water market}

It would be foolish to focus solely on the successes of the water market in agriculture (particularly the temporary market) if the ambition is to gain lessons about the potential for urban water markets. If policymakers are seriously considering the usefulness of markets between urban water customers, a balanced view would also draw upon some of the acknowledged failings of Australia's rural water trade.

There is little doubt that the major challenge confronting water markets in Australia has been the underestimated complexity of water-property rights. Commencing with the original decision to validate all sleeper and dozer rights under the Murray-Darling Basin cap-and-trade scheme, legislators have been constantly playing 'catch-up' in an effort to correct one property-right deficiency after another (see, for example, Quiggin 2001). For instance, the rights to return flows from irrigation continue to remain disputed and are largely misunderstood (or ignored) by those promoting the spurious concept of water-use efficiency. Similarly, the failure to account for the connectivity between surface water and 
groundwater with equally stringent regulation has left some jurisdictions with the formidable task of compensating irrigators for the impacts of multiple administrative failures - first, in the over-allocation of surface water and now because of the over-allocation of groundwater.

Defining water rights with precision is difficult enough in the first place, let alone when multiple jurisdictions are continually subject to pressure from various interest groups with a history of substantial use. The net result has been that demands on behalf of environmental interests, which are purportedly protected by legislation, continue to be undermined.

In addition to the major challenges of settling on adequate property rights and related enforcement has been the limited scope of these markets. In many respects this is the corollary of the strengths described earlier. For instance, the fact that most trade has occurred between agriculturists and thereby eased political resistance to the market approach has also constrained the effectiveness of the market to move water to higher-value uses in other sectors. This issue is given greater attention in the following section.

\section{Scope for urban water markets}

One way to analyse the scope for urban water markets is to consider the motivations for rural water trade and make some assessment about the extent to which these forces are likely to hold in an urban setting. We focus primarily upon household users in the first instance.

It has been argued earlier that one of the primary features that led to a flourishing temporary rural water market was the heterogeneity that typifies modern irrigated agriculture. Combined with the critical nature of this resource for some (but not all) irrigated production and the volumes of water involved in a transaction, these are probably the major considerations in the current debate about the potential of urban water markets.

Unlike agricultural water users, the major determinants of water demand for households are family size, size of land allotment and, to some extent, income (see, for instance, Hoffman et al. 2007). Nevertheless, even a cursory assessment of most urban groups would indicate that there are relatively modest welfare gains from trade between households per se compared to that on offer between different agriculturalists. This observation can only be substantiated by empirical research but, prima facie, households face relatively similar demands for water. Most vary between a low of about 100 kilolitres per year and a high of about 400 kilolitres per annum (ABS 2004). Moreover, there is only limited potential for overcoming the constraints imposed on one group of households by transferring water from other households. After all, indoor demand is generally regarded as non-discretionary for all households and is estimated to be equivalent to about 60 per cent of domestic water use (WSAA 2005). Notwithstanding that 
this figure is, in part, a function of water restrictions that ban outdoor use, the extent to which inter-household trade in its own right could alleviate the constraints imposed by water restrictions is limited. ${ }^{4}$

In line with the arguments presented earlier, it is also worth noting the relative knowledge of potential market participants in an urban water market. This issue has several pertinent components. Unlike their agricultural cousins, urban users might be expected to have only a limited appreciation of hydrological constraints and the implications of these for water delivery and pricing. This is not to imply that there are some supernatural powers bestowed on the irrigation fraternity. Rather, the modest use (and cost) of water by urban residents is unlikely to justify the investments in the knowledge required to be able to discern between water products with different hydrological characteristics. ${ }^{5}$ A similar argument may hold for the limited understanding of the production functions for lawns, gardens and the like. It must be emphasised that this should not serve as a criticism of urban water users or act as a justification for lavish public 'education' programs aimed at such users. The reality is that the price and production-related motivation to gain such knowledge is relatively weak for potential participants in a household urban water market.

We contend that unlike household behaviour and demand, the industrial use of water in urban areas is a more complex question, varying with the nature of production, value of outputs and the like. Relatively little research has been undertaken in the area of non-residential urban water use but anecdotally the quality and reliability of supply are more critical to this group than the price of the input per se. Nevertheless, in some cases industrial users will have incentives to gain knowledge and participate in the market that matches or even surpasses that of irrigators. However, the decision by governments to isolate most industrial water users from urban water restrictions has curtailed the incentive to acquire the knowledge and enthusiasm to participate in a market setting. Were a market to be available to this group, it is also difficult to see an industry champion emerging to limit transaction costs, as was the case with the irrigation sector and the activities of Murray Irrigation Limited and Goulburn-Murray Water. In this context, the state would invariably be expected to fulfil this role.

Notwithstanding the limitations facing inter-household trade and the likely necessity for the state to play a major part in fostering participation by industrial users, there remains considerable scope for trade between the household sector as a whole, industrial users who prize ongoing water access and agricultural users. A comparison of the estimated willingness to pay to avoid urban water

\footnotetext{
${ }^{4}$ By way of contrast, irrigators can treat all of their water allocation as discretionary and exit the industry.

${ }^{5}$ Water and wastewater services account for less than one per cent of household expenditure in most states (Edwards 2008: 153).
} 
restrictions with the going rate for temporary rural water allocations in parts of eastern Australia provides some support for this view. For example, Brennan et al. (2006) estimate that the household impacts of water restrictions are between $\$ 347$ and \$870 per season in Perth. In a similar vein, Hensher et al. (2006) report a household willingness to pay $\$ 239$ per year to avoid water restrictions. To provide a rough basis for comparison, it is worth noting that in 2004/05 Australian households consumed on average 103 kilolitres per capita in total. This equates to about 300 kilolitres for an average three-person household or less than a third of one megalitre of water. By way of contrast, the going rate for temporary access to a megalitre of 'raw' water currently stands at about $\$ 300$ (see, for example, Watermove 2008), although this varies across the irrigation season. Even after accounting for the additional cost of converting raw water to potable water, there should be ample scope for alleviating or lowering water restrictions by trading water away from agriculture into urban areas.

Similar support can be found in the outcomes from a recent inter-sectoral water-trading program in Northern Victoria. In this case, commercial urban users and larger water users responsible for managing community sporting assets (such as bowling clubs, tennis clubs, schools and the like) were afforded the opportunity to enter the temporary rural water market and 'trade their way out of water restrictions'. The popularity of this program and the willingness of participants to pay standard delivery charges on top of the cost of the bulk water purchased are indicative of the potential benefits of inter-sectoral trading activity. Regrettably, few similar cases of trade at this level are available, at least to the knowledge of the authors.

Of course, all water trades are contingent on some form of interconnection between users. There is some doubt that this will ever be feasible for all jurisdictions. For instance, Victoria already enjoys interconnection between different sectors and the planned north-south pipeline should expand this 'grid' of connectivity. By way of contrast, the scope for interconnectivity between agricultural water users and the urban residents of Sydney seems remote in the context of current water prices. The point here is that any program of reform adopted on a national scale should at least consider this most rudimentary principle. ${ }^{6}$ There seems little point in insisting on national standards for inter-sectoral trade where interconnection is never likely to be feasible in some jurisdictions.

In addition to physical connectivity, two additional conditions need to be met to ensure the operation of the urban-rural trade. First, trade between sectors

\footnotetext{
${ }^{6}$ It can be argued that the reluctance of Tasmania and Western Australia to become signatories to the National Water Initiative hinged partly on the irrelevance of sections of the reform package to these jurisdictions. For example, nationally consistent water entitlements will count for little in Tasmania until a cheap means of exporting water to the mainland is discovered.
} 
needs to be politically acceptable or run the risk of stalling. Second, the institutions charged with actually delivering water to purchasers must have sufficient incentives to honour such trades. Regrettably, both of these conditions remain as significant obstacles in some states. Water traded to urban users from willing agricultural sellers continues to be described in the press as 'taking water' and dubious water-for-infrastructure swaps are put in place to appease those who claim to be disaffected (see, for example, DSE 2008). In some jurisdictions the function of bulk water delivery has yet to be adequately separated from agricultural interests, resulting in inequitable treatment of water users regardless of the status of validly purchased water access rights.

\section{Other market issues}

Accompanying the discussion about urban water trade are a range of arguments that focus on urban water pricing. Popular in this context are calls for the use of 'scarcity pricing' to replace urban water restrictions (see, for instance, Grafton and Kompas 2007). The basic idea is that water prices should be permitted to vary in the short term to reflect the relative scarcity of the resource. Accordingly, higher prices would help choke off demand, rather than relying on punitive restrictions which impose welfare costs. In addition, the higher prices would act as a clearer incentive to drive investments in alternative infrastructure.

These arguments would have greatest credibility if genuine and complete inter-sectoral access to the available resources had been achieved or where inter-sectoral transfers are not feasible at all. Put simply, the welfare gains from scarcity pricing are likely to be severely limited unless, in the first instance, wholesale scarcity is addressed using the most cost-effective alternatives. For those jurisdictions with the opportunity for inter-sectoral trade, focusing on scarcity pricing at the household level has the potential to divert attention from the substantive gains on offer from higher-level reform. Where sectoral connectivity is problematic, clearly scarcity pricing has a more useful role ${ }^{7}$ and should be pursued.

A second strand of arguments about urban water trade centres on the institutional design of a competitive water industry and the role of the private sector within this regime. Notwithstanding the intuitive appeal of competition, most of these questions require empirics to guide decision-makers. In addition, much of this analysis needs to be undertaken on a jurisdiction-by-jurisdiction basis, since results from these types of studies are heavily influenced by geographical variations. To the best of our knowledge, very little empirical work

\footnotetext{
${ }^{7}$ It is worth noting the Grafton and Kompas (2007) show that scarcity pricing in Sydney would obviate the need for water restrictions, but that the city would still confront critical water shortages without significant augmentation works.
} 
is available at this scale to guide the discussion and a great deal more work should be undertaken as part of settling on a national reform agenda in this field.

\section{Concluding remarks}

Urban water markets are clearly part of the wider Australian water-reform agenda. The mounting enthusiasm for urban water markets can be traced to at least two sources - the broad success of urban-utility reform in other sectors and the accomplishments of the rural water market. This paper has focused primarily on the latter of these motivations. In essence, we have argued that many of the features that have buttressed the success of rural water markets are absent from a potential household-to-household water market. Nevertheless, there is unquestionably scope for markets in the context of wider inter-sectoral redistribution of the resource and this should be regarded as the 'low-hanging fruit' $^{\prime}$ in the water-reform orchard of some jurisdictions.

In addition, the experience with rural water markets gives some indication of the challenges associated with property rights and the political and institutional changes that would be required to support an urban water market. It would be unwise to underestimate the magnitude of these problems.

Modifications to urban water pricing also has merit, but this should not be considered in isolation. Overcoming the Balkanised approach to different water users (Freebairn 2005) should be the major focus of immediate reform. Similarly, there are a range of industry design issues ranging from the extent of private-sector involvement to the level of competition at different stages of the supply chain. In this instance, decisions should be based on sound empirical understanding and an appreciation of political realities. Regrettably, the latter tend to be in more plentiful supply than the former when it comes to urban water reform.

\section{References}

ABS 2004, 'Water Account, Australia', Canberra, Australian Bureau of Statistics.

Brennan, D. 2006, 'Water policy reform in Australia: Lessons from the Victorian seasonal water market', Australian Journal of Agricultural and Resource Economics 50(3): 403-23.

Brennan, D., Tapsuwan, S. and Ingram, G. 2007, 'The welfare costs of urban outdoor water restrictions', Australian Journal of Agricultural and Resource Economics 51(3): 243-62.

DSE 2008, 'Protecting the food bowl's future', Melbourne, Department of Sustainability and Environment. 
Edwards, G. 'Urban water management', in L. Crase, (ed.) Water policy in Australia: The impact of change and uncertainty, Resources for the Future Press, Washington.

Freebairn, J. 2005, 'Early Days with water markets', Industry Economic Conference. Melbourne.

Grafton, Q. and Kompas, T. 2007, 'Pricing Sydney Water', Australian Journal of Agricultural and Resource Economics 51(3): 227-42.

Hensher, D., Shore, N. and Train, K. 2006, 'Water supply security and willingness to pay to avoid drought restrictions', Economic Record 82(256): 56-66.

Hoffmann, M., Worthington, A. and Higgs, H. 2006, 'Urban water demand with fixed volumetric charging in a large municipality: The case of Brisbane, Australia', Australian Journal of Agricultural and Resource Economics 50: 347-59.

Musgrave, W. 2007, 'Historical Development of Water Resources in Australia: Irrigation in the Murray-Darling Basin', in Crase (ed.) op. cit.: 28-43.

National Water Commission 2005, 'Overview of the National Water Initiative', Canberra, National Water Commission. Available at: http://www.nwc.gov.au/nwi/index.cfm\#trading

PC 2008, 'Towards urban water reform: A discussion paper', Melbourne, Productivity Commission.

Quiggin, J. 2001, 'Environmental economics and the Murray-Darling river system', Australian Journal of Agricultural and Resource Economics 45(1): 67-94.

RIRDC 2007, 'The economic and social impacts of water trading: Case studies in the Victorian Murray Valley', Canberra, Rural Industries Research and Development Corporation. 